\title{
PENDAMPINGAN KELUARGA PENERIMA MANFAAT PROGRAM KELUARGA HARAPAN DALAM PEMBENTUKAN KELOMPOK USAHA BERSAMA (KUBE) DI KECAMATAN BENGKAYANG KABUPATEN BENGKAYANG KALIMANTAN BARAT
}

\author{
Sabinus Beni*, Blasius Manggu, Yosua Damas Sadewo \\ Program Studi Kewirausahaan \\ Institut Shanti Bhuana \\ Jalan Bukit Karmel No.1 Bengkayang, Kalimantan Barat \\ Email Korespondensi: * sabinusbeni@gmail.com
}

Received : November 13, 2020 ; Accepted : December $2^{\text {nd }}, 2020$; Published : January $1^{\text {st }}, 2021$

\begin{abstract}
Abstrak
Kegiatan pengabdian kepada masyarakat dilakukan di Desa Bani Amas Kecamatan Bengkayang Kalimantan Barat dengan sasaran keluarga pra sejahtera penerima bantuan bersyarat Program Keluarga harapan dengan tujuan dari program kemitraan masyarakat ini adalah untuk memberikan pelatihan dan pendampingan pendirian kelompok usaha bersama (KUBE) keluarga penerima manfaat Program Keluarga Harapan (PKH) di Kecamatan Bengkayang secara terus menerus baik ditinjau dari proses pembuatan proposal hingga sampai pada beroperasionalnya KUBE. Fenomena yang terjadi darii pertama dilakukannya kegiatan sampai berakhirnya kegiatan pendampingan selama enam bulan efektif, keluarga penerima manfaat program keluarga harapan $(\mathrm{PKH})$ belum bisa bergerak lebih jauh untuk mencapai kemandirian sebagaimana yang telah dicita-citakan oleh Kementerian Sosial dengan menumbuhkan semangat berwirausaha melalui kelompok usaha bersama (KUBE). Mitra program kemitraan masyarakat ini adalah melakukan pembentukan 11 (sebelas) Kelompok Usaha Bersama (KUBE) Program Keluarga Harapan Kecamatan Bengkayang di Kabupaten Bengkayang sampai pendampingan pembuatan proposal bantuan KUBE yang siap diajukan ke Kementerian Sosial melalui Dinas Sosial Kabupaten Bengkayang. Metode kemitraan yang digunakan adalah memberikan pelatihan berupa ceramah, tutorial dan diskusi serta pembuatan proposal usaha.
\end{abstract}

Kata Kunci: Kemiskinan, wirausaha, mandiri, pendampingan

Abstract
Community service activities are carried out in Bani Amas Village, Bengkayang District, West Kalimantan with the aim of poor families receiving conditional assistance. Hopeful Family Program with the aim of this community partnership program is to provide training and assistance in the establishment of joint business groups (KUBE) families of beneficiaries of the Hope Family Program. (PKH) in Bengkayang Subdistrict continuously both in terms of the process of making proposals to the operation of KUBE. The phenomenon that occurs from the first time the activities are carried out until the end of the effective sixmonth mentoring activity, families of beneficiaries of the Hope Family Program (PKH) have not been able to move further to achieve independence as has been envisioned by the Ministry of Social Affairs by fostering a spirit of entrepreneurship through joint business groups (KUBE). The partner of the community partnership program is the formation of 11 (eleven) Joint Business Groups (KUBE) of the Bengkayang District Family Hope Program in 
Bengkayang Regency to assist in making KUBE assistance proposals ready to be submitted to the Ministry of Social Affairs through the Bengkayang Regency Social Service. The partnership method used is providing training in the form of lectures, tutorials and discussions as well as making business proposals.

Keywords : poverty, entrepreneurship, independent, accompaniment

\section{Pendahuluan}

Rendahnya penghasilan keluarga sangat miskin menyebabkan keluarga tersebut tidak mampu memenuhi kebutuhan pendidikan untuk tingkat minimal sekalipun. Alasan terbesar untuk tidak melanjutkan sekolah ialah karena tidak ada biaya, bekerja untuk mencari nafkah, merasa pendidikannya sudah cukup dan berbagai alasan lainnya [1]. Maka dengan itu Program Keluarga Harapan (PKH) Kementerian Sosial Republik Indonesia yang merupakan cikal bakal pengembangan sistem perlindungan sosial, khususnya bagi keluarga miskin, dengan tujuan akhir PKH adalah meningkatkan partisipasi sekolah baik itu sekolah dasar maupun sekolah menengah.

Fenomena gerak cepat pemerintah dalam melakukan pembangunan mulai dari desa sebagai perwujudan komitmen untuk mengembangkan Indonesia secara merata layak untuk direspon secara positif, terutama oleh masyarakat di Kecamatan Bengkayang [2]. Kecamatan Bengkayang memiliki 385 Keluarga Penerima Manfaat (KPM) yang dari tahun 2014 sampai 2018 belum ada KPM yang keluar/graduasi mandiri dari kepesertaan PKH karena belum sejahtera atau tingkat kesejahteraan KPM belum meningkat, hal inilah yang mendasari dipilihnya Kecamatan Bengkayang Kabupaten Bengkayang sebagai daerah yang menjadi obyek dalam program pengabdian pada masyarakat ini, sehingga diharapkan masyarakat peserta PKH Kecamatan Bengkayang di daerah ini memiliki pengetahuan yang memadai untuk dapat membentuk Kelompok Usaha Bersama (KUBE) sehingga membentuk perilaku manajemen pemasaran dan keuangan yang bijak dan pada akhirnya dapat meningkatkan kesejahteraan hidupnya.

Berdasarkan uraian analisis diatas, maka rumusan permasalahan yang dihadapi mitra adalah bagaimana meningkatkan pemahaman KPM di Kecamatan Bengkayang tentang pembuatan proposal KUBE yang terencana dan tersistematis. Kegiatan PPM ini dilakukan selama Tahun 2018 di Desa Setia Budi dan Desa Bani Amas Kecamatan Bengkayang Kabupaten Bengkayang Provinsi Kalimantan Barat.

Beberapa kegiatan pengabdian kepada masyarakat terkait pemberdayaan KPM PKH antara lain; Program Kelompok Usaha Bersama belum sepenuhnya terlaksana secara efektif karena mekanisme yang dijalankan masih mengalami berbagai masalah seperti sosialisasi yang belum dilaksanakan secara rutin, penentuan kelompok sasaran yang tidak sesuai kriteria, ketidaksesuaian modal dengan jenis usaha, penyuluhan keterampilan berusaha tidak dilakukan secara kontinue, proses pendampingan/ pembimbingan tidak rutin dilaksanakan [3].

Dengan adaya KUBE, masyarakat akan mendapatkan kemitraan untuk membuat kegiatan yang pada akhirnya akan dapat mendatangkan perbaikan ekonomi serta memberikan manfaat yang lebih bagi para anggotanya, baik manfaat secara finansial, maupun manfaat kebersamaan dan kegotong royongan yang saat ini sudah mulai pudar di masyarakat desa [4].

Jangka pendek dari program pemberdayaan adalah terwujudnya pemenuhan kebutuhan dasar masyarakat sasaran pemberdayaan sedangkan untuk tujuan jangka panjang adalah peningkatan kualitas dan kemandirian masyarakat sasaran pemberdayaan didalam usaha ekonomi produktif dan kelembagaannya [5]. 


\section{Metode}

Kegiatan Pengabdian Kepada Masyarakat ini dilakukan di Desa Setia Budi dan Desa Bani Amas Kecamatan Bengkayang Kabupaten Bengkayang Kalimantan Barat, dimulai pada tanggal 10 April 2018 diawali dengan Sosialisasi Kelompok Usaha Bersama (KUBE) oleh Dinas Sosial, Pemberdayaan Perempuan, dan Perlindungan Anak Kabupaten Bengkayang serta pendampingan setiap bulan sampai tanggal 11 November 2018. Jarak lokasi kegiatan pengabdian dari kampus Shanti Bhuana $\pm 18,9 \mathrm{KM}$ atau sekitar 42 menit perjalanan darat melalui jalan rusak dan berlumpur, jarak menuju lokasi dapat dilihat pada gambar dibawah ini.

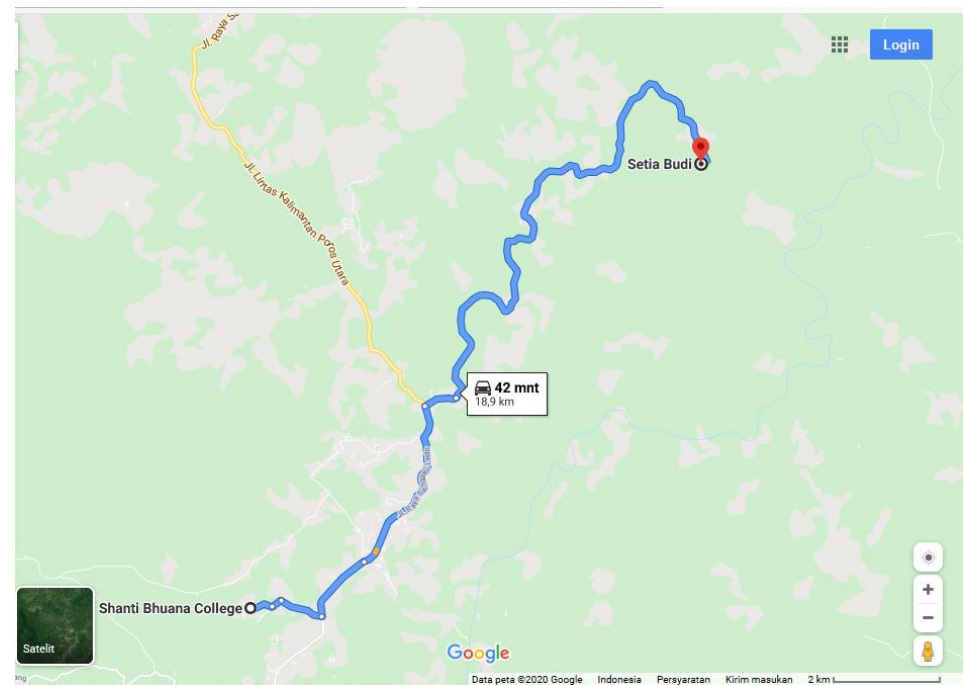

Gambar 1. Google Map dari Kampus ke Lokasi Pengabdian

Alat dan Bahan yang digunakan dapat dilihat sebagai berikut: Materi PPT tentang Kelompok Usaha Bersama (KUBE), Laptop, ATK (Buku, Pulpen, dan Pensil), Kertas Manila, dan Lahan Kebun Praktek. Pelaksanaan kegiatan Program Pengabdian pada Masyarakat ini dilakukan dengan menggunakan metode ceramah, tutorial, dan diskusi. Adapun tahapan pelaksanaan kegiatan program kemitraan masyarakat ini adalah Sosialisasi oleh Dinas Sosial, PP dan PA Kabupaten Bengkayang, Ceramah dan Diskusi, Pendampingan.

Tanggal 10 April 2018 kegiatan pertama diawali dengan Sosialisasi oleh Dinas Sosial, PP dan PA Kabupaten Bengkayang yang dihadiri oleh 153 KPM, unsur desa dan pendamping PKH, setelah kegiatan sosialisasi selesai dilakukan, materi disampaikan oleh Tim pelaksana kegiatan pengabdian (Sabinus Beni) terkait dengan perencanaan usaha dan pembuatan proposal usaha. Peserta diberikan wawasan mengenai kewirausahaan dan manajemen pengelolaan usaha bersama, Peserta diberikan materi tentang penyusunan perencanaan proposal sederhana dan kegiatan operasional usaha sehari-hari, Peserta diberikan kesempatan untuk mendiskusikan permasalahan yang berkaitan dengan pengelolaan usaha bersama dengan tujuan saling memberikan tanggapan untuk perbaikan pengelolaan usaha kelompok serta pembentukan Kelompok KUBE sebanyak 11 kelompok yang langsung disahkan oleh Kepala Desa Setia Budi dan Kepala Desa Bani Amas. 


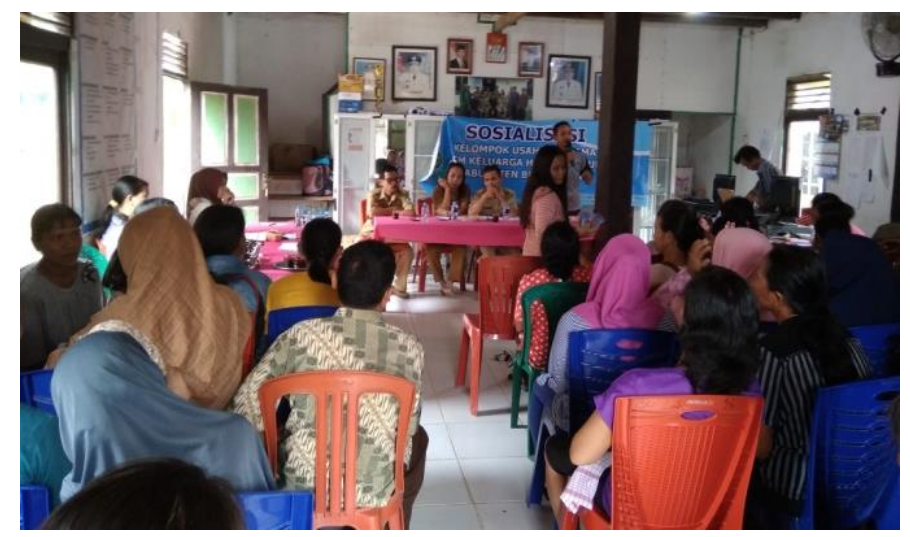

Gambar 2. Kegiatan Sosialisasi KUBE Oleh

Dinsos,PP dan PA Kab. Bengkayang

Kegiatan berikutnya pendampingan pembuatan proposal KUBE hingga proposal siap diajukan ke Dinas Sosial, PP dan PA Kabupaten Bengkayang untuk diteruskan kepada Kementerian Sosial, dalam kegiatan pendampingan tersebut dilakukan hingga bulan November 2018 dengan cara melakukan kegiatan Pertemuan Kelompok 1 (satu) bulan sekali untuk memastikan bahwa kelompok berjalan dengan baik dan proposal benar-benar dapat dan siap diajukan untuk mendapatkan bantuan. monitoring dilakukan dengan memantau perkembangan kelompok serta realisasi proposal dengan disetujuinya 8 (delapan) dari 11(sebelas) kelompok untuk diberikan bantuan dengan nominal masing-masing kelompok mendapatkan Rp20.000.000 (dua puluh juta rupiah).

\section{Hasil dan Pembahasan}

Mayoritas masyarakat di daerah lokasi pengabdian merupakan keluarga Pra Sejahtera yang tidak berani memulai berwirausaha karena takut akan kegagalan usaha dan tidak memiliki modal serta pengalaman untuk memulai usaha (bisnis) [6]. Kondisi ini jika dibiarkan terus menerus akan berdampak kurang baik bagi tujuan $\mathrm{PKH}$, dimana tujuan program PKH kesehatan yaitu untuk ikut serta meningkatkan upaya perbaikan status kesehatan ibu dan anak, khususnya masyarakat miskin [7]. Dengan adanya program ini perlu adanya dampingan dari pendamping peserta $\mathrm{PKH}$ dalam mengevaluasi dan memonitoring peserta dan aliran bantuan sudah sesuaikah dengan tujuan dari program dan apakah sudah dipenuhi persyaratan penerima bantuan atau peserta PKH [8].

Pengabdian pada masyarakat ini dapat dilihat dari beberapa hal yaitu :

1) Sosialaisasi Pembentukan Kelompok bersama pihak PPKH dan Dinas Sosial, PP dan PA

Kabupaten Bengkayang.

Sosialisasi terkait KUBE dilakukan oleh Bidang Sosial secara langsung dihadiri oleh Kepala Bidang Sosial dan Kasi Perlindungan dan Jaminan Sosial serta Koordinator Kabupaten dan Pendamping PKH Kecamatan Bengkayang yag dihadiri oleh 153 KPM di Desa Setia Budi dan Desa Bani Amas serta seluruh aparatur Desa Setia Budi dan Desa Bani Amas. Kegiatan sosialisasi berjalan dengan lancar serta berbagai tanggapan dari peserta yang menunjukkan antusiasme peserta dalam menyambut rencana pembentukan KUBE [9]. 


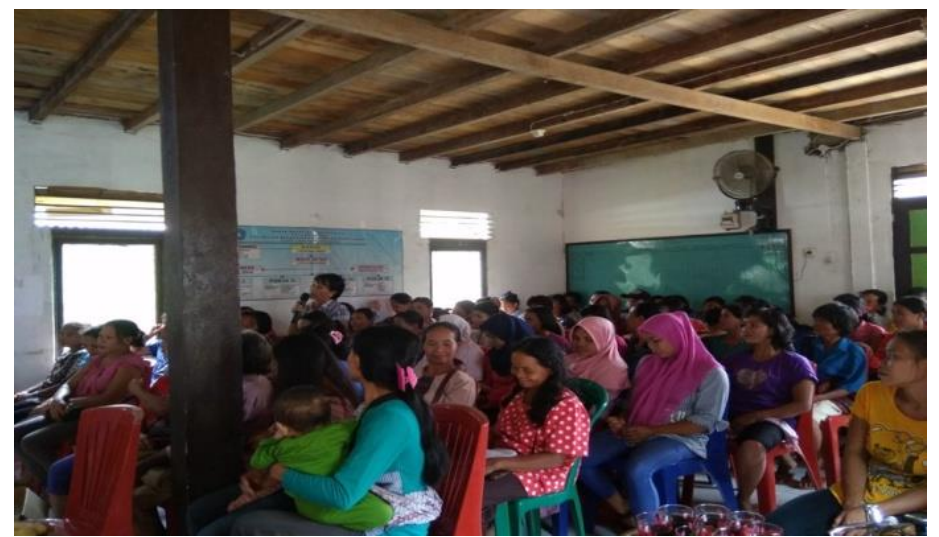

Gambar 3. Dokumentasi Kegiatan Sosialisasi Pembentukan KUBE

2) Pembentukan Kelompok Usaha Bersama

Kegiatan berikutnya setelah dilakukan sosialisasi dilanjutkan dengan pembentukan Kelompok KUBE sebanyak 11 (sebelas) kelompok, antara lain:

a. Kelompok Semangak, Jenis Usaha Kuliner Kerupuk.

b. Kelompok Sungai Rape, Jenis Usaha Ternak Babi.

c. Kelompok Maju, Jenis Usaha Perkebunan Jagung.

d. Kelompok Damong, Jenis Usaha Ternak Babi.

e. Kelompok Sejati, Jenis Usaha Perkebunan Jagung.

f. Kelompok Seteger, Jenis Usaha Ternak Ayam.

g. Kelompok Bongkang Atas, Jenis Usaha Perkebunan Jagung.

h. Kelompok Bongkang Bawah, Jenis Usaha Perkebunan Jagung

i. Kelompok Tapang Sentagi, Jenis Usaha Perkebunan Jagung

j. Kelompok Sentagi Dalam, Jenis Usaha Perikanan (Ikan Air Tawar)

k. Kelompok Temonong, Jenis Usaha Ternak Babi

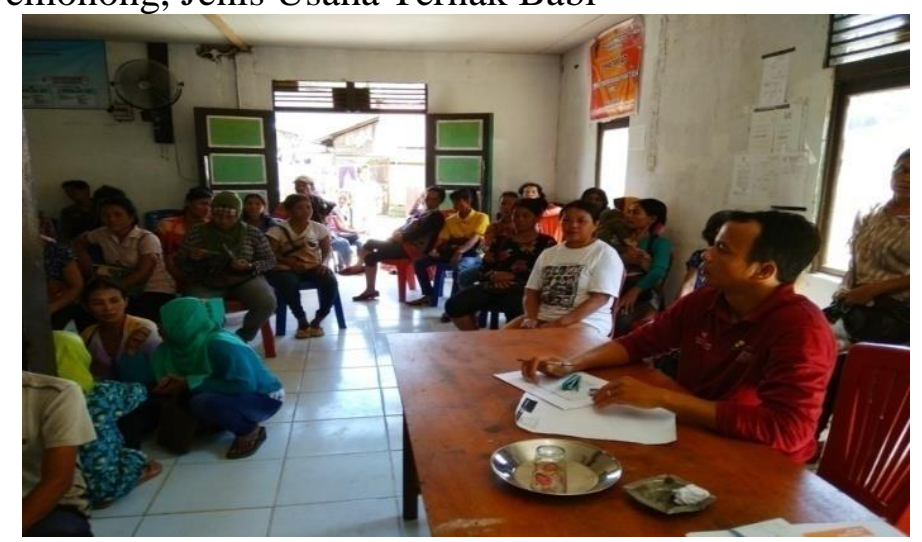

Gambar 4. Dokumentasi Kegiatan Pembentukan KUBE

3) Pembuatan Proposal Kelompok (11 Kelompok)

Pembuatan proposal dilakukan pendampingan oleh Tim Pengabdian bekerjasama dengan Pendamping PKH Kecamatan Bengkayang dari bulan April hingga bulan Mei 2018 hingga proposal siap diajukan kepada Kementerian Sosial melalui Dinas Sosial, PP dan PA Kabupaten Bengkayang. Masing-masing proposal mengajukan sebanyak Rp20.000.000 sesuai kelompok dan jenis usaha berdasarkan pagu maksimal dari Kementerian Sosial [10].

4) Rapat Rutin setiap Bulan

Untuk memastikan kegiatan kelompok berjalan dengan baik, tim pengabdian bekerjasama dengan pendamping PKH Kecamatan Bengkayang untuk terlibat aktif memantau kegiatan 
pertemuan kelompok secara rutin 1 (satu) kali sebulan dengan tujuan mempererat hubungan anggota kelompok dan memantapkan pelaksanaan kegiatan kelompok dalam menjalankan usaha jika proposal yang diajukan disetujui oleh Kementerian Sosial. Kegiatan rapat rutin setiap bulan sebagai salah satu untuk mencapai tujuan PKH secara umum, yaitu: Meningkatkan taraf hidup keluarga penerima manfaat melalui akses layanan pendidikan, kesehatan dan kesejahteraan sosial; Mengurangi beban pengeluaran dan meningkatkan pendapatan keluarga miskin dan rentan; Menciptakan perubahan perilaku dan kemandirian keluarga penerima manfaat dalam mengakses layanan kesehatan dan pendidikan serta kesejahteraan sosial; Mengurangi kemiskinan dan kesenjangan; Mengenalkan manfaat produk dan jasa keuangan formal kepada Keluarga Penerima Manfaat. Kegiatan pertemuan kelompok terlihat pada gambar di bawah ini.

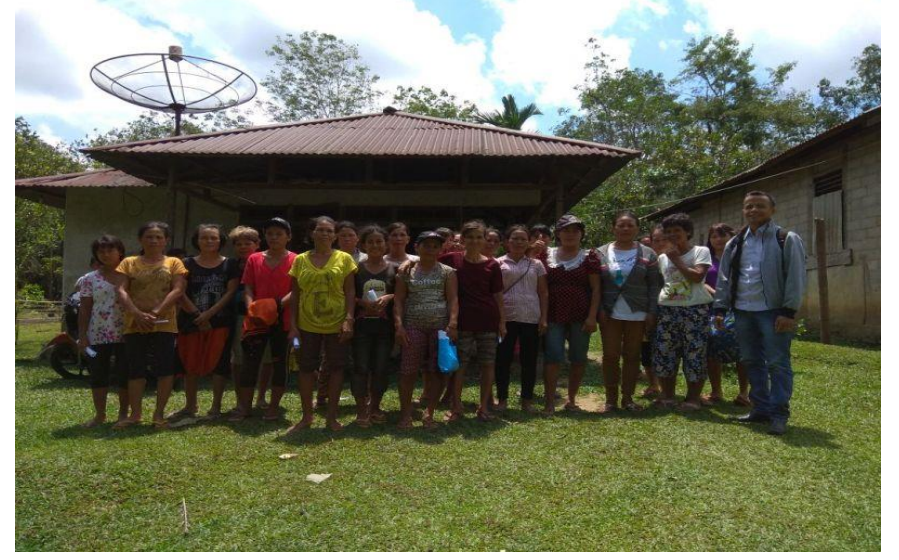

Gambar 5. Dokumentasi Rapat Rutin Kelompok

5) Manajemen Arus Kas dan Manajemen Usaha Bersama yang Berkelanjutan

Manajemen arus kas dan manajemen usaha bersama dilakukan pada saat kegiatan monitoring dan evaluasi kegiatan pengabdian yang dilaksanakan pada saat pertemuan kelompok rutin setiap bulan serta selalu memastikan dan mengontrol apakah kelompok usaha berjalan dengan baik atau tidak, terutama persiapan lahan dan lokasi usaha sebelum dicairkannya proposal oleh Dinas Sosial, PP dan PA kabupaten Bengkayang. Monitoring dan Evaluasi kegiatan Kelompok: berdasarkan hasil monev yang dilakukan dari 11 (sebelas) kelompok terdapat 8 (delapan) kelompok yang disetujui oleh Dinas Sosial untuk dilakukan pencairan bantuan KUBE sebesar Rp20.000.000. (dua puluh juta rupiah) per kelompok.

Secara umum, tingkat kesulitan pelaksanaan kegiatan terletak pada penguasaan teknologi dan pemahaman pembuatan proposal. Hal ini terjadi karena mayoritas KPM PKH adalah penduduk miskin yang berpendidikan SMP kebawah yang kurang melek teknologi sehingga kesulitan dalam membuat proposal menggunakan laptop dan harus didampingi oleh tim pengabdian bersama pendamping PKH Kecamatan Bengkayang sampai proposal benarbenar siap untuk diajukan kepada Kementerian Sosial [11]. Tingkat keberhasilan program sangat bagus, dari jumlah peserta sebanyak $153 \mathrm{KPM}$ PKH menghadiri kegiatan sosialisasi dan pembentukan Kelompok KUBE atau 100\% dari total KPM di Desa Setia Budi dan Desa Bani Amas, dengan terbentuknya 11 Kelompok yang beranggotakan 153 orang dengan hasil akhir proposal yang disetujui oleh Kementerian Sosial melalui Dinas Sosial, PP dan PA Kabupaten Bengkayang sebanyak 8 dari 11 kelompok masing-masing Rp20.000.000 per kelompok.

Sebagai upaya dalam penyelesaian masalah mitra, kami cantumkan dalam diagram fishbhone berikut ini: 


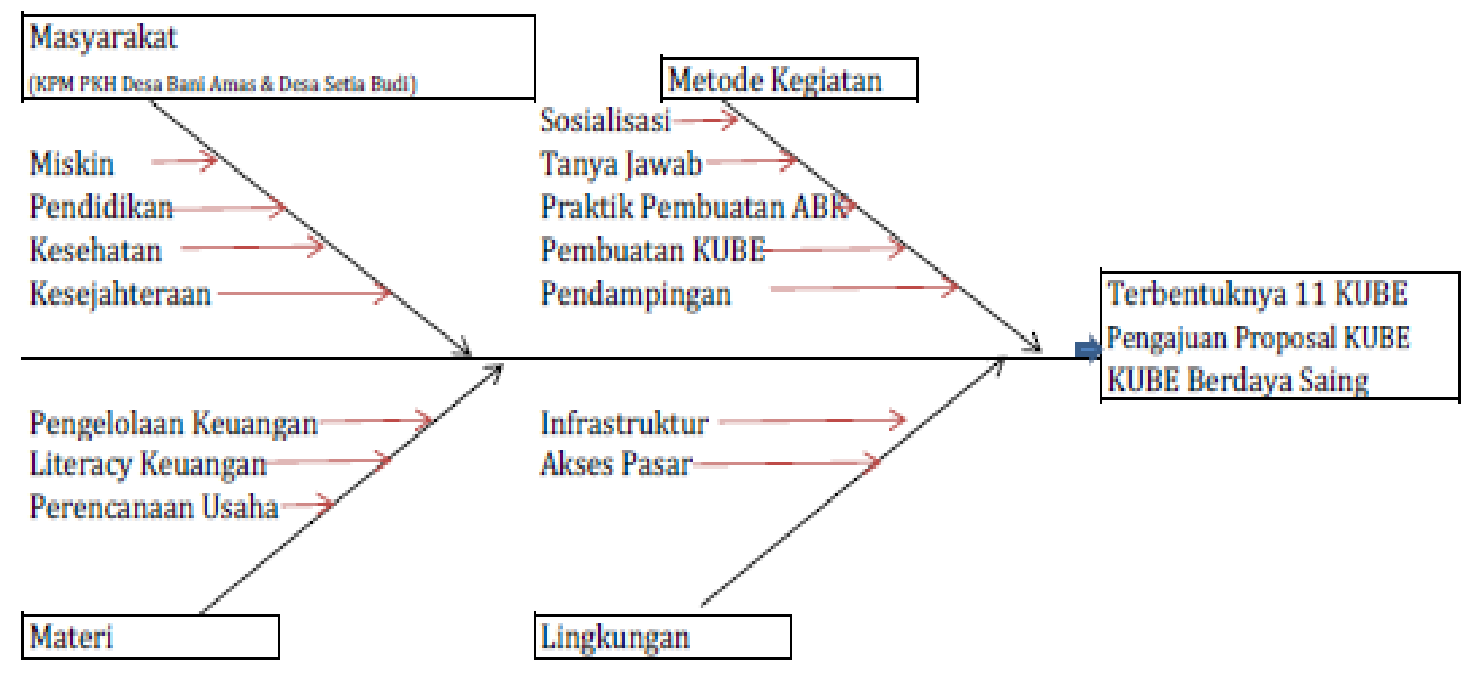

Fishbone Chart untuk permasalahan Mitra KPM PKH Di Desa Bani Amas dan Setia Budi

\section{Kesimpulan}

Dari Pendampingan ini, dapat kami tarik Kesimpulan: Peserta Program PKH di Desa Bani Amas dan Desa Setia Budi sangat antusias dalam mengikuti Sosialisasi serta membentuk Kelompok Usaha Bersama (KUBE) agar segera keluar dari zona kemiskinan yang selama ini membelenggu keluarga Pra Sejahtera penerima bantuan PKH [12]. Kegiatan ini juga di dukung oleh 2 (dua) kepala desa yaitu Desa Bani Amas dan Desa Setia Budi serta pemerintah Kabupaten dan Kecamatan Bengkayang yang di fasilitasi oleh Pendamping Sosial PKH Kecamatan Bengkayang. Dengan tingkat keberhasilan 100\% dalam pembentukan 11 kelompok dan tingkat keberhasilan pelaksanaan kelompok sebesar $72,73 \%$ ditinjau dari disetujuinya 8 dari 11 Kelompok melalui pencairan uang bantuan KUBE sebesar Rp20.000.000 per kelompok atau sebesar Rp160.000.000 untuk 8 (delapan) kelompok KUBE.

Dalam upaya tindak lanjut dari kegiatan ini, dapat kami sampaikan beberapa saran antara lain: Perlu pendampingan khusus agar KUBE berjalan secara berkelanjutan dan dapat mengentaskan kemiskinan, Memaksimalkan peran penyuluh pertanian, agar hasil usaha dapat semaksimal mungkin dan dapat merubah mental bergantung kepada orang lain dan Pemberian modal usaha dengan tanpa bunga kepada pelaku usaha khususnya KPM PKH. Pemberdayaan berdasarkan kearifan lokal yang memanfaatkan sumber daya lokal untuk meningkatkan kesejahteraan anggota kelompok [13].

\section{Daftar Pustaka}

[1] S. Beni and B. Manggu, "Peran Credit Union Dalam Bidang Agribisnis Untuk Pembangunan Pertanian dan Ekonomi," JURKAMI, vol. 2, no. 2, pp. 103-111, 2017.

[2] BPS, Kabupaten Bengkayang Dalam Angka 2019, 2019th ed. Bengkayang: BPS Kabupaten Bengkayang, 2019.

[3] R. Firdaus and K. Reski, "Implementasi Program Kelompok Usaha Bersama (KUBE) Di Desa Lauwa Kecamatan Belopa Utara Kabupaten Luwu," in Seminar Hasil Penelitian (SNP2M) 2018, 2018, p. 36.

[4] S. Rohima, Muklis, and F. Marisa, "Inisiasi Kelompok Usaha Bersama (KUBE) Bagi Penjahit Di Desa Kerinjing, Kecamatan Tanjung Raja, Kabupaten Ogan Ilir," J. Pengabdi. Sriwij., no. 28, 2018.

[5] I. Imron, M. S. Soeady, and H. Ribawanto, "Pemberdayaan Masyarakat Miskin Melalui Kelompok Usaha Bersama (Studi pada Kelompok Usaha Bersama di Desa Dawuhan, Kecamatan Poncokusumo, Kabupaten Malang)," J. Adm. Publik, vol. 2, no. 
3, p. 485, 2018.

[6] S. Beni and B. Manggu, "Efektivitas Program Keluarga Harapan Dalam Penanggulangan Kemiskinan Di Perbatasan (Studi Kasus Kecamatan Jagoi Babang Kabupaten Bengkayang Kalimantan Barat)," Sosio Konsepsia, vol. 9, no. 2, p. 162, 2020.

[7] S. Beni and G. Rano, "Credit Union Sebagai Penggerak Ekonomi Masyarakat Dayak Kalimantan Barat,” Pros. Int. Congr. I Dayak Cult. 1, vol. 1, no. 1, pp. 168-177, 2017.

[8] S. Beni, Pembangunan Manusia Melalui Pendidikan Dasar Credit Union. Jakarta: Mer-C Publishing, 2017.

[9] S. Beni, B. Manggu, and Y. D. Sadewo, "Cunseling Of Family Financial Management Literacy Program Keluarga Harapan Beneficiaries," Diseminasi, vol. 1, no. 2, pp. 8388, 2019.

[10] H. Y. Sufiana and S. Beni, "Analisis Kinerja Keuangan Pada Credit Union Bonaventura Tempat Pelayanan Ledo," Business, Econ. Entrep., vol. 2, no. 1, p. 10, 2020.

[11] Basrowi, Sukidin, and A. Wiyaka, Pengantar Ilmu Budaya. Surabaya: Insan Cendekia, 2003.

[12] S. Beni and B. Manggu, "Bimbingan Teknis Pengawasan Koperasi Se-Kabupaten Bengkayang Tahun 2019: Manajemen Pengawasan Koperasi," PengabdianMu, vol. 5, no. 1, pp. 67-71, 2019.

[13] S. Wardani, Rianto, and A. F. Nilansari, "Pemanfaatan Sumber Daya Lokal Untuk Meningkatkan UMKM Dusun Pulo Gulurejo," Kacanegara, vol. 3, no. 2, p. 99, 2020. 